\title{
Structural study of the interaction of vanadate with the ligand 1,2-dimethyl-3-hydroxy-4-pyridinone (Hdmpp) in aqueous solution
}

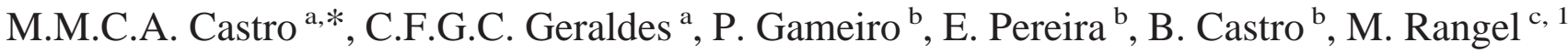 \\ ${ }^{a}$ Departmento de Bioquímica, Faculdade de Ciências e Tecnologia, e Centro de Neurociências, Universidade de Coimbra, 3000 Coimbra, Portugal \\ ${ }^{\mathrm{b}}$ CEQUP/Departamento de Química, Faculdade de Ciências, Universidade do Porto, 4169-007 Porto, Portugal \\ ${ }^{\mathrm{c}}$ CEQUP/Instituto de Ciências Biomédicas de Abel Salazar, Universidade do Porto, 4099-003 Porto, Portugal
}

Received 16 October 1999; accepted 20 December 1999

\begin{abstract}
The interaction of vanadate with the ligand 1,2-dimethyl-3-hydroxy-4-pyridinone (Hdmpp) was studied in aqueous solution using a combination of multinuclear NMR and EPR spectroscopies, as well as potentiometry and cyclic voltammetry. The different species in solution were identified and characterized, and their $\mathrm{p} K_{\mathrm{a}}$ values and stability constants determined. The vanadium complexes formed in solution are strongly dependent on media composition (ionic strength, presence of buffer), $\mathrm{pH}$ and metal-to-ligand ratio (M:L). Two major species $\mathrm{V}(\mathrm{V}) / \mathrm{dmpp}$ and $\mathrm{V}(\mathrm{V}) /(\mathrm{dmpp})_{2}$ — are formed in a $140 \mathrm{mM} \mathrm{NaCl}$ solution within the $\mathrm{pH}$ range 4.5 to 9.0 , when $\mathrm{M}: \mathrm{L}=1: 2$. In the presence of excess ligand ( $\mathrm{M}: \mathrm{L} \leq 1: 5)$, only the $1: 2$ complex is present, and at $\mathrm{pH}<4$ paramagnetic species are detected by EPR in solution, thus indicating a reducing capacity of the ligand. Cyclic voltammetry shows that redox processes in solution are not just electron transfer, but are accompanied by chemical reactions. The $\mathrm{p} K_{\mathrm{a}}$ values and stability constants were determined both by ${ }^{51} \mathrm{~V}$ NMR spectroscopy and potentiometry. The present results have a particular interest in the understanding of the aqueous solution chemistry in aerobic conditions of bis (1,2-dimethyl3-hydroxy-4-pyridinonato) oxovanadium(IV) complex, $\mathrm{VO}(\mathrm{dmpp})_{2}$, a vanadium compound with potential insulin-mimetic properties. (C)2000 Elsevier Science Inc. All rights reserved.
\end{abstract}

Keywords: Vanadate; 1,2-Dimethyl-3-hydroxy-4-pyridinone

\section{Introduction}

Vanadium salts have proved to lower blood glucose levels in diabetic rats although they have a high toxicity [1]. Since then, research has been undertaken to obtain insulin-mimetic vanadium compounds to be used as oral substitutes of insulin $[2,3]$. Bis (maltolato) oxovanadium(IV) (BMOV) seems to be a very promising drug in the control of diabetes due to its insulin-like effects [2].

The class of ligands known as pyridinones proved to be more effective in the treatment of $\beta$-thalassemia than the pyrones, such as maltol and ethylmaltol, as they are better chelators and exhibit a more convenient way to control the hydrophilic/lipophilic balance (HBL) [4]. Pyridinones, which can be synthesized by reaction of pyrones with primary amines, are particularly attractive for pharmaceutical pur-

\footnotetext{
* Corresponding author.

${ }^{1}$ Also corresponding author.
}

poses since their structures allow tailoring of their HBL without any significant change in the chelating properties, thus facilitating their in vivo uptake.

Taking into account these properties, and with the objective of providing a new family of insulin-mimetic compounds, several 1,2-substituted-3-hydroxy-4-pyridinone oxovanadium(IV) complexes have been synthesized and characterized in the solid state [5]. We have been particularly interested in the solution chemistry of the compound VO(dmpp) $)_{2}$, as Hdmpp (1,2-dimethyl-3-hydroxy-4-pyridinone, see chemical structure in Scheme 1) is the ligand of<smiles>Cc1c(O)c(=O)ccn1C</smiles> 
choice for the treatment of $\beta$-thalassemia, and in this work we present a brief report on the vanadate/Hdmpp system. Identification and characterization of the species in solution, under aerobic conditions, have been achieved by the use of resonance techniques, multinuclear NMR and EPR, as well as potentiometry and cyclic voltammetry.

\section{Experimental}

\subsection{Reagents}

Sodium metavanadate, $\mathrm{NaVO}_{3}$, and vanadyl sulfate trihydrate, $\mathrm{VOSO}_{4} \cdot 3 \mathrm{H}_{2} \mathrm{O}$ were from Sigma, and Hdmpp from ACROS Organics; all were used as received. $\mathrm{D}_{2} \mathrm{O}$ was purchased from Cambridge Isotope Laboratories.

\subsection{Potentiometry}

All potentiometric measurements were carried out with a Crison 2002 pH meter and a Crison 2031 burette controlled by a microcomputer. The electrode assembly consisted of an Orion 900029 double-junction $\mathrm{AgCl} \mid \mathrm{Ag}$ reference electrode, and a Rusell SWL07 glass electrode as indicator. System calibration was performed by the Gran method in terms of hydrogen ion concentration, by titrating solutions of strong acid with strong base. All titrations were carried out under an argon atmosphere in a thermostat-controlled double-walled glass cell; the temperature was controlled at $25.0 \pm 0.1{ }^{\circ} \mathrm{C}$,

Table 1

Stability constants obtained for the system vanadate/Hdmpp ${ }^{\text {a }}$

\begin{tabular}{lllll}
\hline $\log \beta_{111}$ & $\log \beta_{011}$ & $\log \beta_{012}$ & $\log \beta_{112}$ & $\log \beta_{212}$ \\
\hline $10.02 \pm 0.06$ & $4.30 \pm 0.04$ & $8.76 \pm 0.06$ & $14.27 \pm 0.06$ & $17.51 \pm 0.06$ \\
\hline
\end{tabular}

a The equilibria studied are written with the components $\mathrm{H}^{+}, \mathrm{H}_{2} \mathrm{VO}_{4}{ }^{-}$and HL, where HL is the neutral species of Hdmpp. The stability constants of the complexes, formed according to $p \mathrm{H}^{+}+q \mathrm{H}_{2} \mathrm{VO}_{4}{ }^{-}+r \mathrm{HL} \rightarrow$ $\left(\mathrm{H}^{+}\right)_{p}\left(\mathrm{H}_{2} \mathrm{VO}_{4}{ }^{-}\right)_{q}(\mathrm{HL})_{r}^{p-q}$ are denoted $\beta_{p, q, r}$.

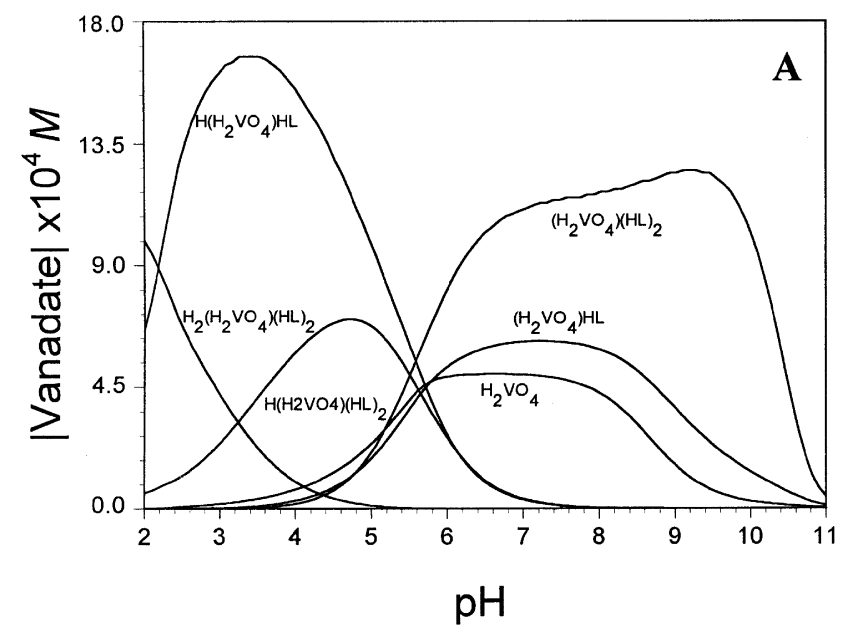

and the ionic strength was adjusted to $0.15 \mathrm{M}$ with sodium chloride.

\subsection{Cyclic voltammetry}

Cyclic voltammetry was carried out at room temperature, under argon, using a EG\&G PAR273A potentiostat. A threeelectrode cell was used, with a platinum microsphere as working electrode, a platinum wire counter electrode and

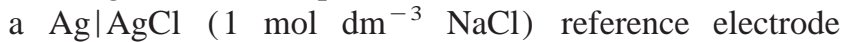
(Metrohm, Ref. 6.0724.140). All solutions were $0.15 \mathrm{~mol}$ $\mathrm{dm}^{-3} \mathrm{NaCl}$, and were studied at scan rates from 20 to $500 \mathrm{mV} \mathrm{s}^{-1}$.

\subsection{NMR spectroscopy}

${ }^{51} \mathrm{~V}$ NMR spectra were obtained on a Varian Unity-500 spectrometer operating at $131.404 \mathrm{MHz}$, at $25.0 \pm 0.5^{\circ} \mathrm{C} .{ }^{51} \mathrm{~V}$ chemical shifts were externally referenced to a $\mathrm{VOCl}_{3}$ solution. The ${ }^{51} \mathrm{~V}$ NMR acquisition parameters were: $33 \mathrm{kHz}$ spectral width, $25 \mu$ s pulse width, $0.5 \mathrm{~s}$ acquisition time and $10 \mathrm{~Hz}$ line broadening.

\subsection{EPR spectroscopy}

EPR measurements were made on a Bruker ESP300E spectrometer, operating at $9 \mathrm{GHz}$. The spectra were calibrated with dpph and the magnetic field using $\mathrm{Mn}^{2+}$ in $\mathrm{MgO}$.

\section{Results and discussion}

\subsection{Potentiometry}

All calculations were performed with SUPERQUAD [6], using published values for the equilibria of $\mathrm{V}(\mathrm{V})$ [7] in water and the acidity constants of Hdmpp [8]. The stability constants obtained for the vanadate/Hdmpp system are shown in Table 1. From these and the acidity constants of the

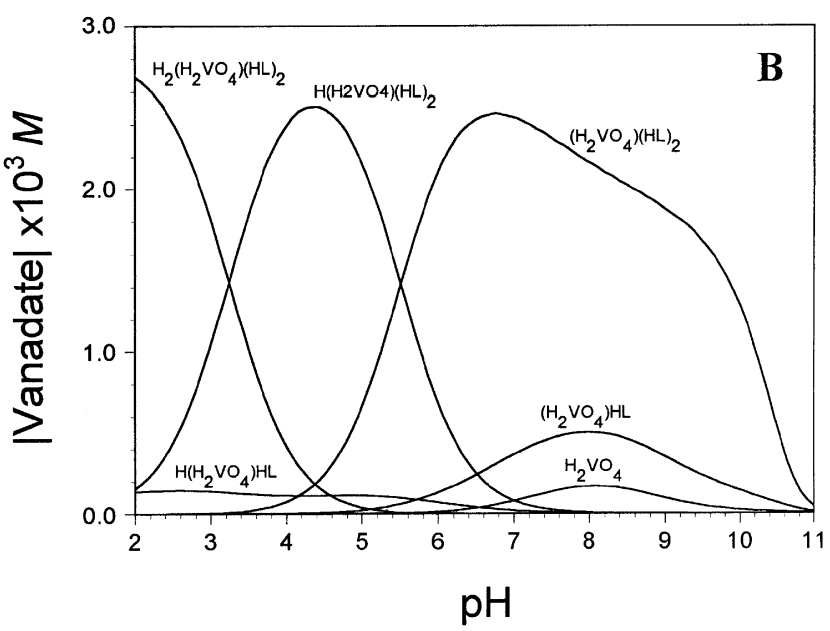

Fig. 1. Distribution diagram for the system V(V)/Hdmpp at different M:L ratios: (A) 1:1 and (B) 1:3. 
ligand and vanadate, we calculated the formation constants of the $1: 1\left(\log K_{\mathrm{VO}_{2}}^{\mathrm{VO}_{2} \mathrm{~L}}=12.70\right)$ and $1: 2\left(\log K_{\mathrm{VO}_{2}}^{\mathrm{VO}_{2} \mathrm{~L}_{2}}=21.12\right)$ complexes. The calculated $\mathrm{pH}$ distribution diagrams for metal/ligand (M:L) ratios of 1:1 and 1:3 are depicted in Fig. 1 ; inspection of this figure shows that $\mathrm{VO}_{2} \mathrm{~L}$ is the predominant form for $\mathrm{M}: \mathrm{L}=1: 1$ at low $\mathrm{pH}(80 \%$ at $\mathrm{pH} 3)$, whereas the $1: 2$ complex $\left[\mathrm{VO}_{2} \mathrm{~L}_{2}\right]^{-}$occurs preferentially in ligand excess conditions ( $83 \%$ at $\mathrm{pH} 6.5$, when $\mathrm{M}: \mathrm{L}=1: 3$ ). Representative schematic structures of the two complexes are shown in Scheme 2. The possible hydolyzed and/or protonated forms, as well as the possible isomers, are not taken into consideration, and will be the object of a future publication.

\subsection{Cyclic voltammetry}

Variable $\mathrm{pH}$ cyclic voltammetry was performed in aqueous solutions of $\mathrm{V}(\mathrm{IV}) / \mathrm{dmpp}(1: 2)$ and $\mathrm{V}(\mathrm{V}) / \mathrm{dmpp}(1: 2)$. Several redox processes are detected in the potential range -0.6 to $+0.8 \mathrm{~V}$ (versus $\mathrm{Ag} \mid \mathrm{AgCl}$ ). In the range -0.4 to $-0.2 \mathrm{~V}$ and above $+0.5 \mathrm{~V}$ they correspond to irreversible ligand reduction and oxidation. In the potential range +0.2 to $+0.5 \mathrm{~V}$, one quasi-reversible $\mathrm{V}(\mathrm{IV}) / \mathrm{V}(\mathrm{V})$ redox process is detected, which is strongly $\mathrm{pH}$ dependent. Its irreversibility is probably due to a coupled chemical reaction, as oxidation is usually followed by solvolysis. The $\mathrm{pH}$ dependence arises from the existence of different complexes in solution at different $\mathrm{pH}$ values and redox states, as shown by the speciation curves for the two redox states [8]. Chemical irreversibility is minimized in both redox states at $\mathrm{pH} 3$, which correspond to concentration maxima of the two 1:1 complexes, VOL and $\mathrm{VO}_{2} \mathrm{~L}$. Thus, the 1:1 complexes suffer less severe structural reorganization during the redox processes than the 1:2 complexes.

\subsection{NMR spectroscopy}

The ${ }^{51} \mathrm{~V}$ NMR spectra show that at physiological $\mathrm{pH}$, an aqueous solution of vanadate/Hdmpp (1:2) has the same ${ }^{51} \mathrm{~V}$ signals as a $\mathrm{VO}(\mathrm{dmpp})_{2}$ solution under aerobic conditions [8]: a sharp signal at $-502 \mathrm{ppm}$ for the 1:1 complex, and a broader signal at $-476 \mathrm{ppm}$ for the $1: 2$ complex. In the presence of a large excess of ligand ( $\mathrm{M}: \mathrm{L} \leq 1: 5)$, both solutions exhibit only one ${ }^{51} \mathrm{~V}$ NMR signal attributable to the 1:2 species. Systematic ${ }^{51} \mathrm{~V}$ NMR studies of vanadate/Hdmpp at variable $\mathrm{pH}$ and $\mathrm{M}: \mathrm{L}$ ratios were also performed. The species detected were in general agreement with the distribution diagrams obtained form the protonation and stability constants determined by potentiometry.

\subsection{EPR spectroscopy}

The presence of V(IV) species in the solutions of vanadate/Hdmpp was checked as a function of M:L and $\mathrm{pH}$ using<smiles></smiles>

$\left[\mathrm{VO}_{2} \mathrm{~L}\right]$<smiles></smiles>

$\left[\mathrm{VO}_{2} \mathrm{~L}_{2}\right]^{-}$
EPR. For a large ligand excess $(\mathrm{M}: \mathrm{L} \leq 1: 5)$ at $\mathrm{pH}>6$ the $\mathrm{V}(\mathrm{V}) 1: 2$ species $\left(\mathrm{VO}_{2}(\mathrm{dmpp})_{2}\right)^{-}$is the only one present in solution as the samples are EPR silent, while at $\mathrm{pH}<6$ the solution exhibits an EPR spectrum identical to the one observed for the complex $\mathrm{VO}(\mathrm{dmpp})_{2}$, This result is indicative of the reducing capacity of the ligand.

\section{Conclusions}

The present results show that for the vanadate/Hdmpp system under aerobic conditions, the various vanadium species formed in solution are strongly dependent on $\mathrm{pH}$ and metal-to-ligand (M:L) ratio. For $\mathrm{M}: \mathrm{L}=1: 2$ and at $\mathrm{pH}>6.5$, the species present in solution are the $\mathrm{V}(\mathrm{V})$ 1:1 hydroxocomplex $\left(\mathrm{VO}_{2}(\mathrm{dmpp})(\mathrm{OH})\left(\mathrm{H}_{2} \mathrm{O}\right)^{-}\right)$and the $1: 2 \mathrm{com}-$ plex $\left(\mathrm{VO}_{2}(\mathrm{dmpp})_{2}{ }^{-}\right)$. At $\mathrm{pH}<6.5$, the $1: 1$ complex $\left(\mathrm{VO}_{2}(\mathrm{dmpp})\left(\mathrm{H}_{2} \mathrm{O}\right)_{2}\right)$ predominates. For $\mathrm{M}: \mathrm{L} \leq 1: 5$, at $\mathrm{pH}>6$, the $\mathrm{V}(\mathrm{V}) 1: 2$ species $\left(\mathrm{VO}_{2}(\mathrm{dmpp})_{2}{ }^{-}\right)$is the only one present in solution. For the latter conditions and at $\mathrm{pH}<6$, V(IV) species are detected in solution by their EPR spectra and this result is indicative of the reducing capacity of the ligand, as corroborated by XANES results [8].

\section{References}

[1] C.E. Heyliger, A.G. Tahiliani, J.H. McNeill, Science 227 (1985) 1474-1477.

[2] P. Caravan, L. Gelmini, N. Glover, F.G. Herring, H. Li, J.H. McNeill, S.J. Rettig, I.A. Setyawati, E. Shuter, Y. Sun, A.S. Tarcey, V.C. Yuen, C. Orvig, J. Am. Chem. Soc. 117 (1995) 12759-12770.

[3] S. Fujimoto, K. Fujii, H. Yasui, R. Matsushita, J. Takada, H. Sakurai, J. Clin. Biochem. Nutr. 23 (1997) 113.

[4] R. C. Hider, A. D. Hall, in: Perspectives on Bioinorganic Chemistry, vol. 1, JAI Press, Stanford, 1991, pp. 209-253.

[5] J. Burgess, B. Castro, C. Oliveira, M. Rangel, W. Schlindwein, Polyhedron 16 (1997) 789-794.

[6] P. Gans, A. Sabatini, A. Vacca, J. Chem. Soc., Dalton Trans. (1985) 1195-1200.

[7] K. Elvingson, A. Baró, L. Pettersson, Inorg. Chem. 35 (1996) 3388 3393.

[8] M. Rangel, W. Schlindwein, unpublished results. 